\title{
Effect of different implant placement depths on crestal bone levels and soft tissue behavior: A 5-year randomized clinical trial
}

\author{
Rafael Amorim Cavalcanti de Siqueira ${ }^{1,2}$ (i) | Robson Savaget Gonçalves Junior ${ }^{1}$ | \\ Paulo Gustavo Freitas dos Santos ${ }^{1}$ | Ivete Aparecida de Mattias Sartori ${ }^{1}$ | \\ Hom-Lay Wang ${ }^{2}$ (D) | Flavia Noemy Gasparini Kiatake Fontão ${ }^{1}$
}

${ }^{1}$ ILAPEO College, Curitiba, Brazil

${ }^{2}$ Department of Periodontics and Oral Medicine, University of Michigan School of Dentistry, Ann Arbor, MI, USA

Correspondence

Hom-Lay Wang, Department of Periodontics and Oral Medicine, University of Michigan School of Dentistry, 1011 North University Avenue, Ann Arbor, Michigan 48109-1078, USA.

Email: homlay@umich.edu

\begin{abstract}
Objectives: This randomized clinical trial analyzed the long-term (5-year) crestal bone changes and soft tissue dimensions surrounding implants with an internal tapered connection placed in the anterior mandibular region at different depths (equi- and subcrestal).

Materials and methods: Eleven edentulous patients were randomly divided in a splitmouth design: 28 equicrestal implants (G1) and 27 subcrestal $(1-3 \mathrm{~mm})$ implants (G2). Five implants were placed per patient. All implants were immediately loaded. Standardized intraoral radiographs were used to evaluate crestal bone (CB) changes. Patients were assessed immediately, 4, 8, and 60 months after implant placement. The correlation between vertical mucosal thickness (VMT) and soft tissue recession was analyzed. Sub-group analysis was also performed to evaluate the correlation between VMT and CB loss. Rank-based ANOVA was used for comparison between groups $(\alpha=.05)$.
\end{abstract}

Results: Fifty-five implants (G1 $=28$ and $G 2=27$ ) were assessed. Implant and prosthetic survival rate were $100 \%$. Subcrestal positioning resulted in less CB loss $(-0.80 \mathrm{~mm})$ when compared to equicrestal position $(-0.99 \mathrm{~mm})$, although the difference was not statistically significant $(p>.05)$. Significant CB loss was found within the G1 and G2 groups at two different measurement times (T4 and T60) $(p<.05)$. Implant placement depths and VMT had no effect on soft tissue recession $(p>.05)$.

Conclusions: There was no statistically significant difference in $\mathrm{CB}$ changes between subcrestal and equicrestal implant positioning; however, subcrestal position resulted in higher bone levels. Neither mucosal recession nor vertical mucosa thickness was influenced by different implant placement depths.

\section{KEYWORDS}

bone level osseointegration, bone loss, bone remodeling, dental implant, dental implant platform-switching, immediate dental implant loading, soft tissue, subcrestal 


\section{1 | INTRODUCTION}

Marginal bone loss around dental implants is a common occurrence that can be accelerated by surgical trauma during flap elevation and bone osteotomy for implant placement. In addition, bone remodeling occurs during the establishment of the peri-implant supracrestal tissue attachment (Berglundh \& Lindhe, 1996; Cosyn, Sabzevar, \& De Bruyn, 2012; Oh, Yoon, Misch, \& Wang, 2002; Spinato et al., 2019). A current major challenge in implant therapy is to minimize crestal bone (CB) loss around implants since this has been proven to be essential for soft tissue stability and long-term success of the implant treatment (Fu, Lee, \& Wang, 2011; Novaes, Barros, Muglia, \& Borges, 2009; Tarnow, Cho, \& Wallace, 2000). The implant-abutment interface design and location in relation to the bone crest (Koutouzis, Neiva, Nair, Nonhoff, \& Lundgren, 2014; Romanos, Aydin, Gaertner, \& Nentwig, 2015; Vervaeke et al., 2018; Weng et al., 2008), the amount of keratinized mucosa (Lin, Chan, \& Wang, 2013; Perussolo, Souza, Matarazzo, Oliveira, \& Araujo, 2018; Roccuzzo, Grasso, \& Dalmasso, 2016) and soft tissue thickness have all been suggested to have a direct impact on implant marginal bone loss (Linkevicius, Apse, Grybauskas, \& Puisys, 2009; Linkevicius et al., 2018; Linkevicius, Puisys, Steigmann, Vindasiute, \& Linkeviciene, 2015; van Eekeren, van Elsas, Tahmaseb, \& Wismeijer, 2017). Recent studies have also described the role of abutment height in establishing peri-implant biological distance and as a contributing factor toward peri-implant bone changes (Galindo-Moreno et al., 2016; Novoa et al., 2017; Spinato et al., 2019).

Implants with an internal taper connection and platformswitching can provide better protection against microbial leakage and soft tissue inflammation by reducing the microgap at the implant-abutment interface and increasing the distance to the bone crest, as well as allowing for a greater amount of connective tissue around the implant that functions as a cuff-like barrier (D'Ercole et al., 2014; Khorshidi, Raoofi, Moattari, Bagheri, \& Kalantari, 2016; Lazzara \& Porter, 2006; Tenenbaum, Schaaf, \& Cuisinier, 2003). The subcrestal placement of dental implants may avoid the exposure of implant threads after initial physiologic bone remodeling and allow an adequate esthetic emergence profile for the prosthetic restoration (Koutouzis et al., 2014; Palaska, Tsaousoglou, Vouros, Konstantinidis, \& Menexes, 2016; Vervaeke et al., 2018). Subcrestal implant placement was also suggested to have a positive impact on papilla formation and CB preservation (Novaes et al., 2009). However, one randomized clinical trial (RCT) with a split-mouth design examined platform-switching implants placed sub- and equicrestally and concluded that the different implant placement depths did not influence CB changes (de Siqueira et al., 2017).

Another factor that can influence marginal bone loss is the frequency of exchange of abutments that may disturb the surrounding peri-implant tissues (Rompen, 2012). The "one abutment-one time" protocol (use of one definitive abutment at the time of implant placement) was introduced to overcome potential sequalae of repeated changes of a cover screw or provisional abutments (Canullo, Bignozzi, Cocchetto, Cristalli, \& lannello, 2010; Degidi, Nardi, \&
Piattelli, 2011). However, a systematic review on this topic concluded that despite the potential benefits of this approach on marginal bone level changes, its clinical significance remains uncertain (Atieh, Tawse-Smith, Alsabeeha, Ma, \& Duncan, 2017).

Indeed, there is still limited information from clinical studies in humans on the subcrestal placement of dental implants with platform-switching features, and long-term follow-ups are lacking. This randomized controlled trial (RCT) analyzed long-term CB changes and soft tissue dimensions surrounding implants with an internal tapered connection that were placed in the anterior mandible at different depths (equicrestal and subcrestal) and immediately loaded. Clinical and radiographic analyses were performed immediately, 4, 8 , and 60 months after implant placement.

\section{2 | MATERIAL AND METHODS}

\section{1 | Study population}

The study included 11 patients ( 8 females and 3 males) aged 45 to 65 years at time of enrollment (mean age: 57.1 years) that received implant treatment at the ILAPEO College (ILAPEO, Curitiba, PR, Brazil) between 2011 and 2012 with 5 years follow-up. The 8-month outcomes were reported in a previous study (de Siqueira et al., 2017). This study was approved by the ethics committee of the State University of Ponta Grossa (UEPG No. 50/2012, Brazil). All patients were informed about the evidence-based, positive outcome of implant treatment, and the experimental approach of implant placement depths that were tested. Each patient received verbal as well as written information and signed the informed consent.

\section{2 | Inclusion criteria}

Inclusion criteria were good overall health and fully edentulous arches. Within the mandible, each patient had sufficient interforaminal space to allow the placement of five implants with a minimal distance of $7 \mathrm{~mm}$ between implants (center to center) and minimum distance of $3.5 \mathrm{~mm}$ from the mental foramen to the most posterior implants. Adequate bone height for placement of implants with a minimum of $10 \mathrm{~mm}$ length and $3.5 \mathrm{~mm}$ diameter without simultaneous guided bone regeneration was evaluated by means of cone beam computed tomography (CBCT).

\section{3 | Exclusion criteria}

Exclusion criteria were non-controlled diabetes (glycated hemoglobin (HbA1c) values above 7.5\%) (Promsudthi, Pimapansri, Deerochanawong, \& Kanchanavasita, 2005), immunodeficiencies, history of IV bisphosphonate, radiation therapy (up to 5 years before the study), heavy smoking ( $>10$ cigarettes/day), and inadequate bone 
volume for proper implant placement $(<10 \mathrm{~mm}$ vertical length and $<5.5 \mathrm{~mm}$ ridge width).

\section{4 | Presurgical treatment}

Treatment allocation is summarized in Figure 1 in accordance with the Consolidated Standards of Reporting Trials (CONSORT) criteria (Appendix S1). Patients underwent clinical and imaging examination (panoramic, cephalometric, and CBCT scan). All patients were rehabilitated with maxillary complete dentures and mandibular full-arch implant-fixed prostheses (FIFPs). Prior to the surgical procedure, a duplication of the lower denture fabricated during treatment planning was used as the surgical guide. Two implant placement depthsequicrestal and subcrestal-were tested and randomly assigned to each patient under a split-mouth design (i.e., two subcrestal implants and three equicrestal implants or vice versa). A researcher not involved with the surgical and prosthetic parts of the study used a computer-generated random number table for patient allocation (IS). The same researcher secured the random number assigned to each patient that was placed in sealed and opaque envelopes.

\section{5 | Surgical procedure}

Keratinized tissue width (KTW) at the implant placement sites was recorded before the surgical procedures by an examiner blinded to the treatments provided. The blinded examiner was calibrated for better reproducibility of the measurements performed. Vertical mucosa thickness (VMT) was measured at each implant placement site using a \#30 K-file (Dentsply Maillefer, Ballaigues, Switzerland) that was inserted until touching the bone crest. VMT was categorized as thin ( $<2 \mathrm{~mm}$ ) or thick ( $\geq 2 \mathrm{~mm}$ ) (Linkevicius et al., 2015). Details regarding the soft tissue measurements were described in a previous publication (de Siqueira et al., 2017). All patients received a $1 \mathrm{~g}$ dose of amoxicillin and an $8 \mathrm{mg}$ dose of betamethasone $1 \mathrm{hr}$ before surgery. Standardized surgical procedures were performed by the same experienced surgeon (PGFS) for all patients. Fifty-five internal tapered implants (sandblasted and acid-etched surface, Titamax CM, Neodent, Curitiba, PR, Brazil) were placed during this RCT (five implants per patient). The implants were placed at least $3.5-5 \mathrm{~mm}$ anterior to the mental foramens. Implant diameters (3.5-4.3 mm) and length (10-13 mm) were selected based on the local bone availability to ensure a minimum of $1 \mathrm{~mm}$ supporting bone around the implants. An insertion torque $\geq 45 \mathrm{Ncm}$ was required for immediate loading (Thome et al., 2015). In order to avoid excessive osseo-compression, maximum torque was limited to $60 \mathrm{Ncm}$. A wider diameter implant was used when the initial insertion torque was $<45 \mathrm{Ncm}$. Twenty-eight implants were placed equicrestally (G1), and $27 \mathrm{im}$ plants were placed 1-3 mm subcrestally (G2) (Figure 2). The subcrestal placement depth was assessed using the implant insertion handle (Neodent). The surgical procedure and drilling protocol were standardized for both groups. The prosthetic abutment height (mini conical abutments, Neodent) was selected taking into consideration that the prosthetic margin should be placed at the level of the mucosa. Healing caps were placed and flaps were closed without tension using 5/0 interrupted Nylon sutures (Ethicon US, Somerville, NJ, USA). All patients were prescribed $0.12 \%$ chlorhexidine digluconate rinse (Noplak, Daudt, Rio de Janeiro, RJ, Brazil), 500 mg of amoxicillin (twice a day for 7 days), and 500 mg acetaminophen (if needed for pain control).

\section{6 | Prosthetic procedure}

Prosthetic procedures and prostheses fabrication followed a previously described technique and were performed by the same prosthodontist (RACS) (Borges, Dias Pereira, Thome, Melo, \& de Mattias Sartori, 2010; Thome et al., 2015). New maxillary complete dentures were fabricated for all patients. A cast rigid bar was fabricated for the mandibular hybrid prosthesis using a passive fitting technique (Lee et al., 2012). The framework bar was waxed over a dimensionally larger brass cylinder than the titanium cylinder that was later cemented to the framework using resin cement (Panavia F; Kuraray Co., Ltd, Tokyo, Japan). Acrylic resin and acrylic teeth were then used to fabricate the mandibular hybrid full-arch implant-fixed prosthesis. Forty-eight hours after implant installation healing caps were removed, and the screw-retained prostheses were delivered. Patients were given oral hygiene instructions and returned for follow-up 10 days after surgery. All prostheses were then removed for suture removal. Following surgical treatment, the patients were recalled at $4,8,12$, and 16 weeks, as well as at 8 months, for control and oral hygiene instructions. Recall visits were then every 6 months for reinforcement of oral hygiene instructions and supragingival plaque removal during a follow-up period of 5 years. Maintenance protocol at the ILAPEO College consists of prosthesis removal and debridement of implant surfaces with manual Teflon curettes and gently powered rubber prophy cups. Prosthesis was polished with rubber cups for plaque removal. Patients were encouraged to use soft stiffness toothbrushes on prosthetic surfaces and abutment necks. They were also thoroughly instructed on how to use superfloss ${ }^{\circledR}$ (Oral-B, Procter and Gamble Co, Cincinnati, USA) for cleaning under prosthesis and around implants.

\section{7 | Follow-up measurements}

The clinical measurements and radiographic examinations were performed at baseline, 4, 8, and 60 months after surgery. All patients returned for the follow-ups, and the previously described procedures for prosthesis removal and soft tissue measurements were repeated. Pocket probing depth (PPD) was measured to the nearest millimeter using a 10-mm graduated periodontal probe (Williams probe, Millenium, São Caetano do Sul, SP, Brazil), at the mid-facial, mid-lingual, and interproximal surfaces of each implant (4 sites) (Figure 3). The periodontal probe was also used to evaluate peri-implant health status and 
FIGURE 1 Patient screening, recruitment, allocation, and follow-up chart according to the Consolidated Standards of Reporting Trials (CONSORT) criteria
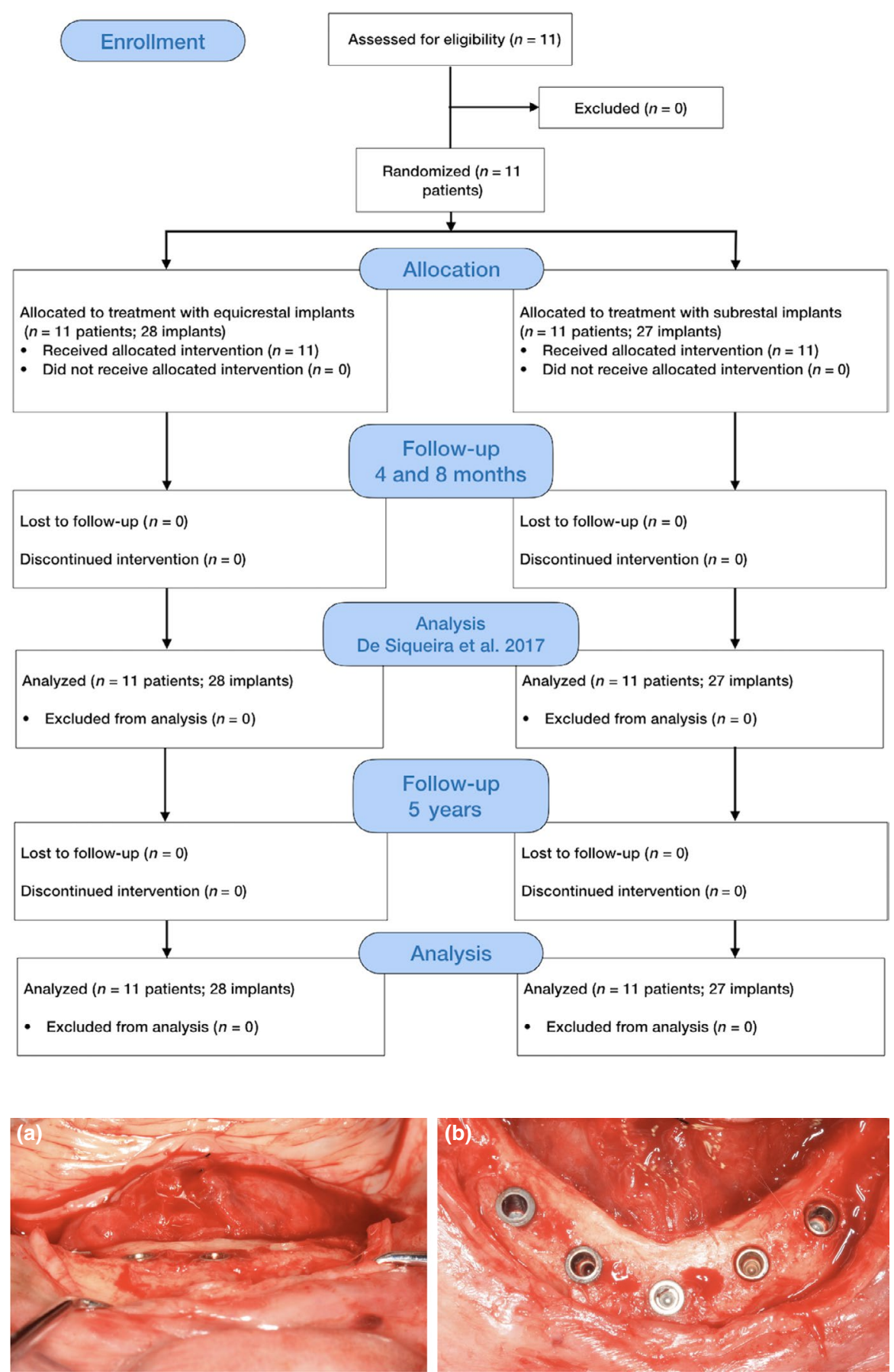

FIGURE 2 Implant placement depth configuration (equicrestal: 1, 2, and 3; subcrestal: 4 and 5). (a) frontal view; (b) occlusal view the degree of soft tissue recession in relation to the abutment position, defined as the distance from the prosthetic abutment margin to the mucosal margin (Renvert, Persson, Pirih, \& Camargo, 2018). Bleeding on probing score (BOP\%) was assessed as the proportion of bleeding sites (dichotomous yes/no evaluation) when stimulated by manual probing with a controlled ( $\sim 25 \mathrm{~g}$ ) force to the bottom of the sulcus/ pocket at the four sites previously described. Intraoral radiographs were taken in high resolution mode (Heliodent Vario, Sirona, Bensheim, Germany) with the aid of a film holder (de Mattias Sartori, Silveira Junior, Fontao, \& Gloria Chiarello de Mattos, 2014) using the parallel technique (Figure 4). Radiographs were taken by the same operator immediately (baseline) after implant placement and at the 4-, 8-, and 60-month follow-up returns (T0, T4, T8, and T60, respectively) (Figure 5). Intraoral radiographs at all time points allowed for the evaluation of $\mathrm{CB}$ changes and specialized software (Sidexis XG 2.5, Sirona) was used for linear measurements of CB changes (de Siqueira et al., 2017). Measurements of the equicrestal implants were performed from the bone crest to the implant-abutment interface. Measurements on subcrestal implants were performed from the most apical region of the radiolucent image to the implant-abutment interface as described in previous article de Siqueira et al. (2017). One calibrated examiner performed all the measurements. Examiner error was evaluated by measuring mesial bone level for all implants at two time points (2 weeks interval). Agreement of values was observed, with no significant systematic error in the 
measurement ( $p=.108$, Wilcoxon test). Dahlberg's error (0.005) indicated low variability in both measurements.

\section{8 | Statistical analysis}

Mean CB changes and VMT among subcrestal and equicrestal implants were statistically analyzed using specialized software with the "f1.Id.f1" function of the software package (SAS University Edition, Cary, NC,

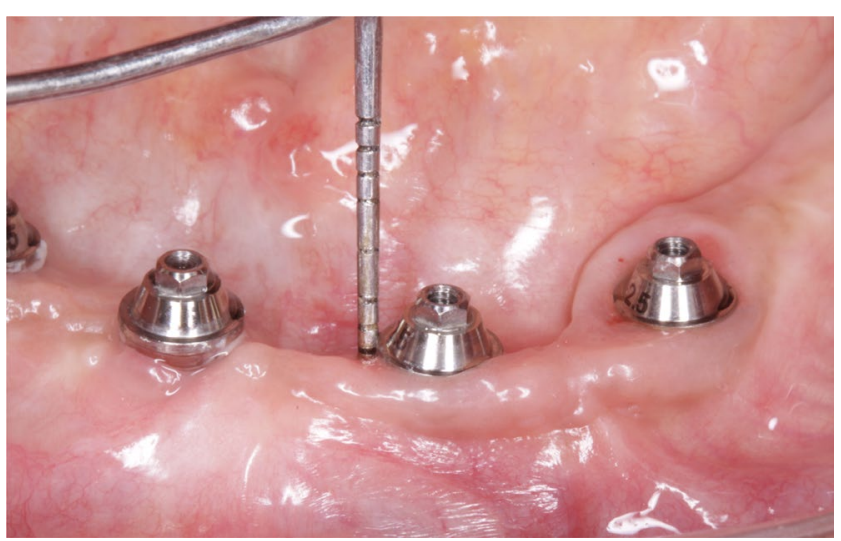

FIGURE 3 Measurement of soft tissue recession from the abutment to the mucosal margin at the T60 follow-up
USA). Mean, standard deviation, median, and range were calculated for each analysis. Statistical analysis of different implant placement depths (equicrestal or subcrestal) and VMT at the three evaluation times (4, 8, and 60 months) was performed using rank-based ANOVA-type statistical test ( $a=0.05$ ) (Brunner, Domhof, \& Langer, 2002). Treatment, time, and interaction between these two factors were tested considering the dependence structure of data (treatment and time clustered within patient). The effect of treatment (subcrestal and equicrestal) with BOP and peri-implant mucositis was assessed by fitting multilevel logistic regression models and using the Wald test (level 1: implants; level 2: patients). A sample size calculation ( $80 \%$ power; significance level of .05) determined that 28 implants per group were required to detect a $0.3 \mathrm{~mm}$ difference in CB changes using a two-tailed Student's $t$ test.

\section{3 | RESULTS}

A total of 11 patients from the previously published 8-month data (de Siqueira et al., 2017) completed a mean follow-up time of $5.1 \pm 0.1$ years. No patients dropped out or were excluded during the follow-up time, and all patients returned for the scheduled follow-up evaluations. No implants or prosthesis were lost within the 60 -month evaluation period, resulting in a $100 \%$ implant and prosthesis survival rate.

CB loss for the two groups at different measurement times (4-, 8-, and 60-month follow-up) is presented in Table 1. Equicrestal

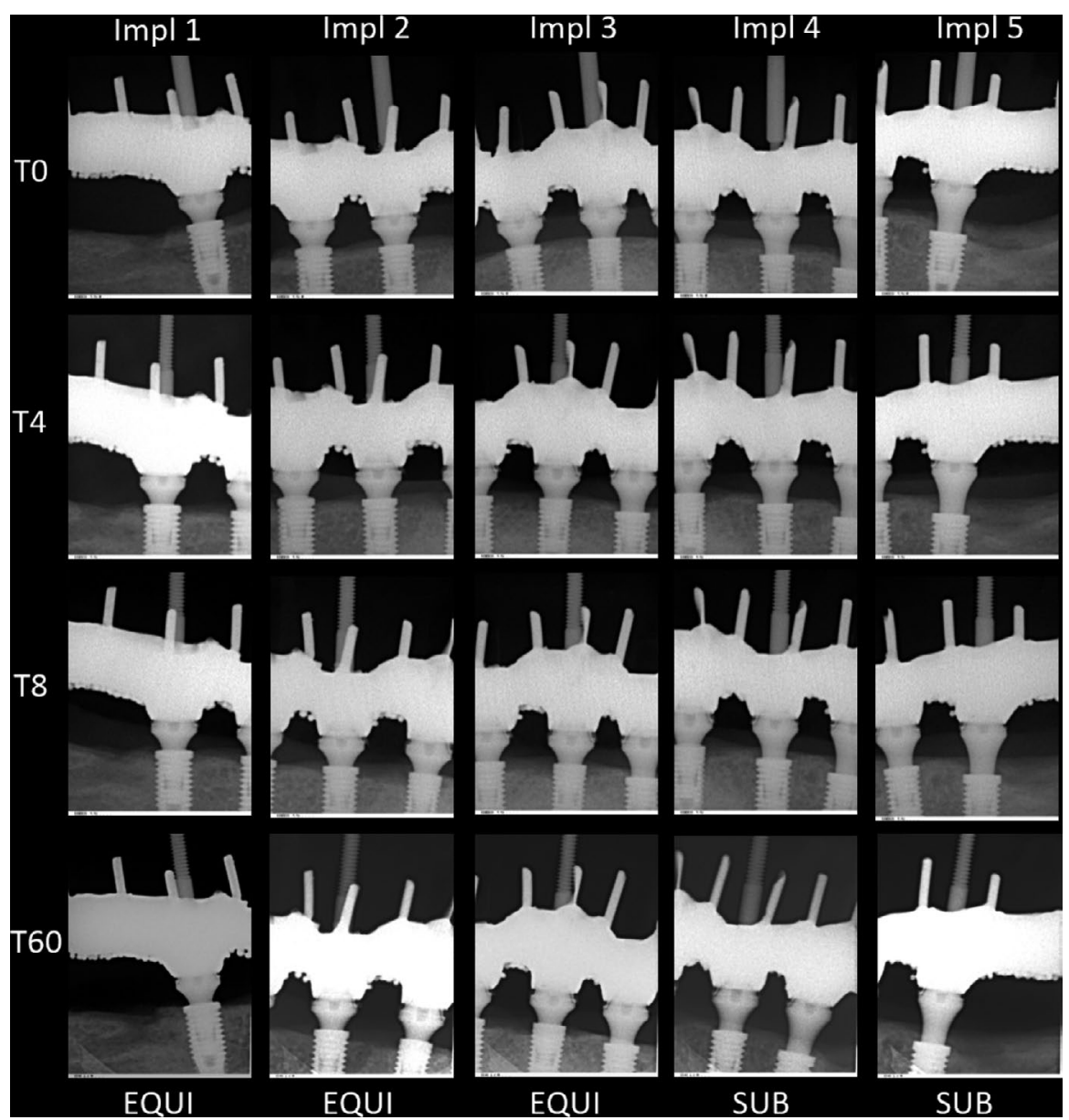

FIGURE 4 Standardized intraoral digital radiographs of equicrestal and subcrestal implants at baseline, 4, 8, and 60 months 
FIGURE 5 Radiographic measurement of crestal bone levels at baseline, 4, 8, and 60 months for: (a) equicrestal implants; (b) subcrestal implants

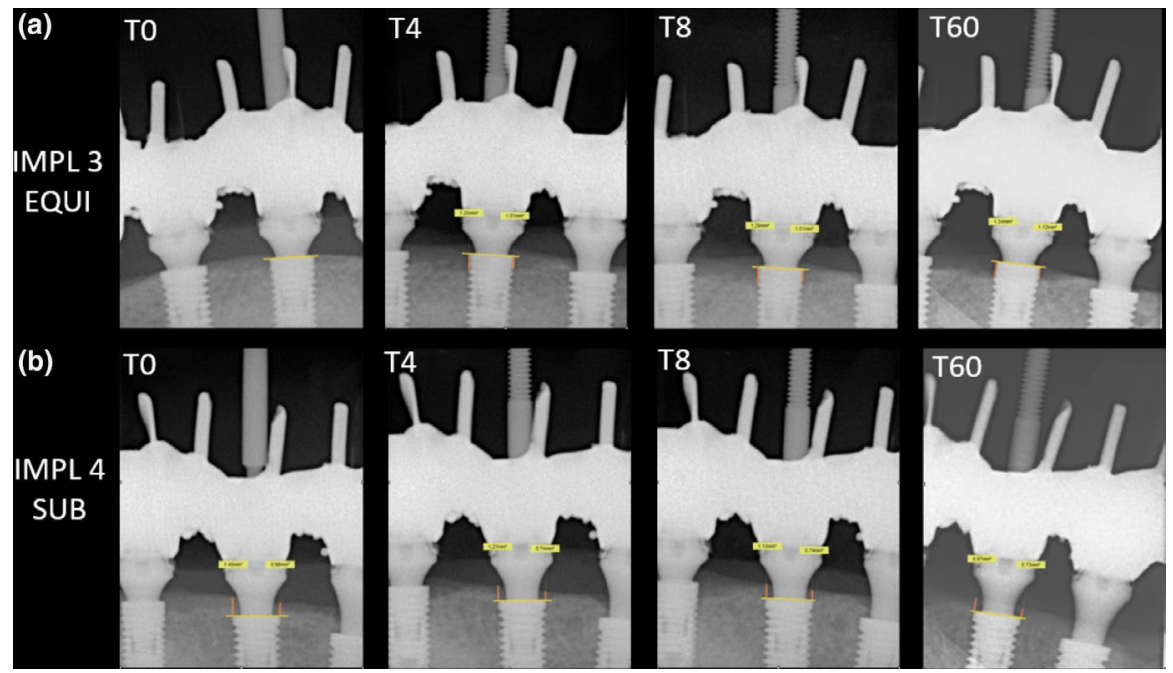

TABLE 1 Crestal bone changes for equi- and subcrestal implants at 4-, 8-, and 60-month evaluations (T4, T8, and T60)

\begin{tabular}{|c|c|c|c|c|c|}
\hline Evaluation times & \multicolumn{2}{|c|}{ Equicrestal Implants } & \multicolumn{2}{|c|}{ Subcrestal Implants } & $\begin{array}{l}p \text {-Value* } \\
\text { (Equicrestal } \times \text { Subcrestal) }\end{array}$ \\
\hline T4 & $0.86 \pm 0.55$ & $0.85(0.23 ; 1.86)$ & $0.50 \pm 0.35$ & $0.47(0.15 ; 1.38)$ & .063 \\
\hline т8 & $1.03 \pm 0.60$ & $1.03(0.19 ; 1.90)$ & $0.66 \pm 0.38$ & $0.61(0.19 ; 1.52)$ & \\
\hline T60 & $0.99 \pm 0.55$ & $0.83(0.46 ; 2.64)$ & $0.80 \pm 0.52$ & $0.70(0.29 ; 2.61)$ & \\
\hline$p$-Value* (T4/T8/T60) & .003 & & & & \\
\hline
\end{tabular}

Note: $p$-Value for interaction between implant type and time: 0.439. T4/T8: $p<.001$, T4/T60: $p=.001$, T8/T60: $p=.334$

Abbreviation: $S D$, standard deviation.

${ }^{*}$ Rank-based ANOVA tests, $p<.05$.

TAB LE 2 Soft tissue recession at the 4-, 8-, and 60-month evaluations

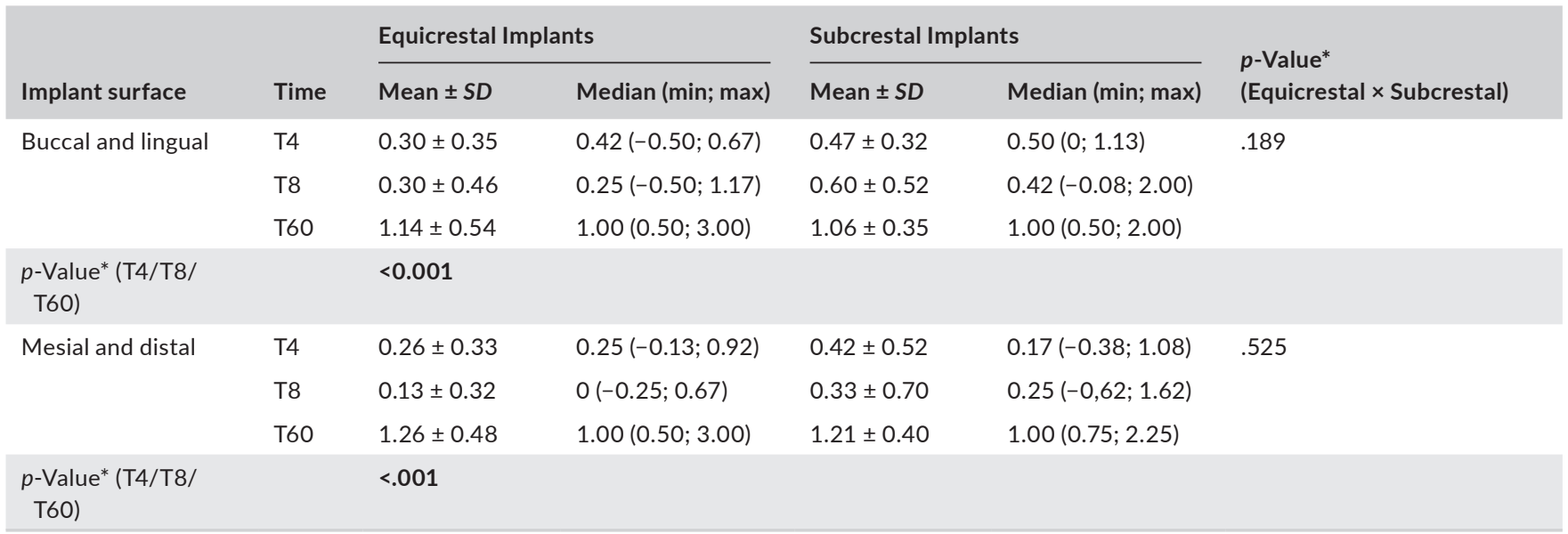

Note: $p$-Value for interaction between implant type and time: 0.273 (buccal and lingual); 0.535 (mesial and distal). Buccal and lingual: T4/T8: $p=.534$, T4/T60: $p<.001$, T8/T60: $p<.001$. Mesial and distal: T4/T8: $p=.138$, T4/T60: $p<.001$, T8/T60: $p<.001$.

Abbreviation: $S D$, standard deviation.

*Rank-based ANOVA tests, $p<.05$.

implants showed higher CB loss than subcrestal implants without a statistically significant difference ( $p>.05)$. Significant CB loss within each group was found when comparing baseline to each time point. However, no significant differences were observed between $\mathrm{T} 8$ and T60 in none of the groups. Moreover, thread exposure occurred only in one implant in the equicrestal group, and there were no thread exposures in the subcrestal group.

Soft tissue recession was assessed at the 60-month evaluation for the two implant placement depth groups (Table 2). Implant placement depths had no effect on the amount of soft 
tissue recession ( $p>.05$ ); however, the analyses within each group showed significant soft tissue recession at the different measurement times (T4, T8, and T60) $(p<.05)$. VMT did not influence the amount of soft tissue recession when evaluated independently of implant placement depth within or between groups (Tables 3 and $4 ; p>.05)$.

The abutment heights utilized in the study and average peri-implant CB loss at the 60-month evaluation are displayed in Table 5. Mean PPD was $2.9 \mathrm{~mm}$ for G1 (equicrestal implants) and $2.7 \mathrm{~mm}$ for $\mathrm{G} 2$ (subcrestal implants). BOP scores as at T4, T8, and T60 were $23.1 \%, 21.4 \%$, and $24.5 \%$, respectively. BOP scores as at T4, T8, and T60 were $23.1 \%, 21.4 \%$, and $24.5 \%$, respectively. No statistically significant difference was found for BOP scores between G1 and $\mathrm{G} 2$ groups at all time points $(p=.926 ; p=.661$ and $p=.926$, respectively).

Progressive bone loss based on radiographic bone level assessment along with signs of inflammation was noted in 2 (equicrestal group) of the 55 implants after 60 -months following the delivery of the prosthesis. These implants were then diagnosed with peri-implantitis (peri-implantitis incidence in this study was $3.6 \%$ at the implant level and $9 \%$ at the patient level). Peri-implant mucositis affected 9 out of the 55 implants (16.4\% at the implant level and 54\% at patient level) with no statistically significant difference between G1 and G2 groups ( $p=$.588) (Berglundh et al., 2018; Renvert et al., 2018).

\section{DISCUSSION}

The short- (4 and 8 months) and long-term (5 years) clinical outcomes suggested that implant placement level (equi- or subcrestally) did not affect the amount of $C B$ changes and both placements can be considered a reliable approach for implant supported fixed prosthesis in the lower arch. To our knowledge, this was the first RCT study which assessed the 5-year clinical outcomes of equi- and subcrestally implant placement in a splitmouth design.

Different bone level measurements were needed for the equicrestal and subcrestal groups because of the different implant placement depths and resulting bone level configuration. Since each implant was compared to itself at baseline and at the 60-month evaluation, $\mathrm{CB}$ changes between the different groups were properly assessed. Any reduction in the bone level compared to the baseline level was considered CB loss.

The results found in this RCT showed there was no significant difference in $\mathrm{CB}$ changes between the two depths of implant placement. Although subcrestal implants had slightly less CB loss when compared to equicrestal implants, no statistically significant difference was noted. This is in agreement with previous studies that demonstrated no statistically significant difference between the two placement depths tested (Al Amri et al., 2017; Koh et al., 2011; Koutouzis et al., 2014; Palaska et al., 2016). Although the placement of subcrestal implants was suggested to minimize bone resorption (Barros, Novaes, Muglia, lezzi, \& Piattelli, 2010; Fetner et al., 2015; Novaes et al., 2009; Pontes et al., 2008; Saleh et al., 2018; Vervaeke et al., 2018; Weng, Nagata, Leite, de Melo, \& Bosco, 2011), a study conducted by Pellicer and coworkers found greater bone loss for subcrestal implants (Pellicer-Chover et al., 2016).

Although no statistical difference in CB levels was found between subcrestal and equicrestal placement, subcrestal implant placement was able to avoid thread exposure for all implants after 5 years. The clinical relevance of this result is that subcrestal placement may reduce the risk of having peri-implantitis by minimizing rough surface exposure (Monje, Galindo-Moreno, Tozum, Suarez-Lopez del Amo, \& Wang, 2016; Schwarz et al., 2017). A similar finding was reported by Vervaeke and coworkers in a 2-year follow-up study (Vervaeke et al., 2018) and in a RCT with 3-year follow-up using platform-switched implants (Al Amri et al., 2017). Once exposed, implants with rough surfaces can facilitate biofilm formation (Pistilli et al., 2018; Teughels, Van Assche, Sliepen, \& Quirynen, 2006).

One group found no difference for subcrestal implant placements of 0.5 or $1.5 \mathrm{~mm}$ and made a logical consideration that it might be sensible to place implants at a depth of $0.5 \mathrm{~mm}$ in order to be able to fully use $1 \mathrm{~mm}$ more of bone support, especially for situations of limited bone heights (Gualini et al., 2017). However, the decision to place a longer implant in a crestal position may not always be the most ideal treatment decision since the risk of peri-implantitis may be increased with exposure of rough implant surfaces. In addition, recent systematic reviews showed that even short implants present similar CB changes and survival rates compared to longer implants (Ravida et al., 2019) and an implant/crown ratio up to 2.2 does not lead to increased complications (Meijer, Boven, Delli, \& Raghoebar, 2018).

The vertical position of the implant-abutment interface, although of extreme importance, does not seem to be the only cause of bone loss, and other factors such as platform-switching, types of connection, timing of abutment placement and height, and soft tissues characteristics should all be taken in account. Compared to non-mismatched implant-abutment connection, internal tapered implants with platform-switching are expected to have lower bone loss due to a reduced microgap at the implant-abutment interface leading to less bacterial leakage and lower stress in the surrounding bone (Castro et al., 2014; D'Ercole et al., 2014). Therefore, implants with non-mismatched connections are not recommended to be placed subcrestally (Broggini et al., 2003; Hermann, Cochran, Nummikoski, \& Buser, 1997; Weng, Nagata, Bosco, \& de Melo, 2011).

Adequate (usually $\geq 2 \mathrm{~mm}$ ) soft tissue thickness and keratinized mucosa width have been reported to lead to healthier peri-implant soft and hard tissues (Grischke et al., 2019), as well as to promote less bone loss, improved oral hygiene (Perussolo et al., 2018), and better mucosal esthetics (Bonino et al., 2018). A subanalysis performed in the present study revealed that VMT $<2 \mathrm{~mm}$ did not affect the bone remodeling around equi- and subcrestal implants 
TAB LE 3 Soft tissue recession for the two levels of baseline vertical mucosal thickness measured at the 4-, 8-, and 60-month evaluations

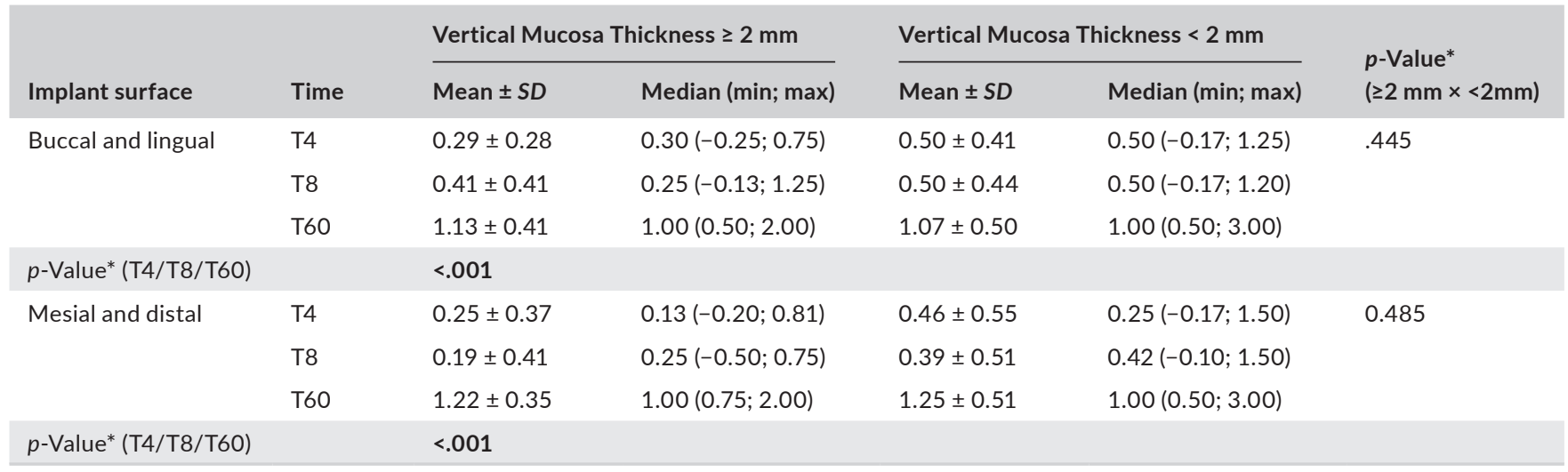

Note: $p$-Value for interation between vertical mucosa thickness and time: 0.272 (buccal and lingual); 0.520 (mesial and distal). Buccal and lingual: T4/ T8: $p=.391$ T4/T60: $p<.001$, T8/T60: $p<.001$. Mesial and distal: T4/T8: $p=.563$, T4/T60: $p<.001$, T8/T60: $p<.001$.

Abbreviation: $S D$, standard deviation.

*Rank-based ANOVA tests, $p<.05$.

TAB LE 4 Crestal bone changes for two levels of vertical mucosal thickness at 4-, 8-, and 60-month evaluations for equi- and subcrestal implants

\begin{tabular}{|c|c|c|c|c|c|c|}
\hline \multirow[b]{2}{*}{ Implants } & \multirow[b]{2}{*}{ Time } & \multicolumn{2}{|c|}{ Vertical mucosa thickness $\geq 2 \mathrm{~mm}$} & \multicolumn{2}{|c|}{ Vertical mucosa thickness $<2 \mathrm{~mm}$} & \multirow{2}{*}{$\begin{array}{l}p \text {-Value* } \\
(\geq 2 \mathrm{~mm} \times<2 \mathrm{~mm}\end{array}$} \\
\hline & & Mean $\pm S D$ & Median (min; max) & Mean $\pm S D$ & Median (min; max) & \\
\hline \multirow{2}{*}{$\begin{array}{l}\text { Subcrestal }(\geq 2 \mathrm{~mm} ; n=14) \\
(<2 \mathrm{~mm} ; n=13)\end{array}$} & T8 & $0.63 \pm 0.48$ & $0.43(0.05 ; 1.54)$ & $0.76 \pm 0.56$ & $0.62(0.18 ; 1.82)$ & \multirow{2}{*}{.457} \\
\hline & T60 & $0.87 \pm 0.61$ & $0.70(0.33 ; 2.61)$ & $0.72 \pm 0.39$ & $0.71(0.29 ; 1.54)$ & \\
\hline \multirow{2}{*}{$\begin{array}{l}\text { Equicrestal ( } \geq 2 \mathrm{~mm} ; \\
\quad n=11)(<2 \mathrm{~mm} ; n=17)\end{array}$} & T8 & $1.23 \pm 0.58$ & $1.27(0.51 ; 2.44)$ & $0.88 \pm 0.76$ & $0.64(0.10 ; 2.27)$ & \multirow{2}{*}{.272} \\
\hline & T60 & $1.01 \pm 0.64$ & $0.85(0.51 ; 2.64)$ & $0.99 \pm 0.50$ & $0.81(0.46 ; 2.23)$ & \\
\hline \multicolumn{2}{|l|}{$p$-Value* (T4/T8/T60) } & \multicolumn{4}{|l|}{.210} & \\
\hline
\end{tabular}

Note: $p$-Value for interation between vertical mucosa thickness and time: 0.195 (subcrestal); 0.472 (equicrestal). Subcrestal: T4/T8: $p<.001$, T4/T60: $p<.001$, T8/T60: $p=.183$.

Abbreviation: $S D$, standard deviation.

*Rank-based ANOVA tests, $p<.05$.

since no statistically significant difference was found. This finding is in agreement with a previous study (Canullo et al., 2017), which concluded that with bone-level platform-switching implants, the tissue thickness appears to have a negligible effect on crestal bone loss. Linkevicius and coworkers in 2010 (Linkevicius, Apse, Grybauskas, \& Puisys, 2010) reported that in presence of thin tissue (<2 mm), platform-switching did not preserve crestal bone better than a traditional implant-abutment connection. More recently, the same group reported that less bone loss occurred in thick tissues $(>2.5 \mathrm{~mm}$ ) when compared to medium $(2.0-2.5 \mathrm{~mm}$ ) and thin ( $<2 \mathrm{~mm}$ ) thicknesses (Linkevicius et al., 2018). In the present study, subanalysis of the effect of keratinized tissue width within the sub- and equicrestal groups was not reported as KM was $\geq 2 \mathrm{~mm}$ in the majority of the implants evaluated. The homogeneous distribution of $\mathrm{KM} \geq 2 \mathrm{~mm}$ could have also contributed to the overall favorable outcomes reported. In addition, most of the crestal bone loss occurred in the first months of follow-up and eventually stabilized with little changes occurring toward the end of the follow-up period. Perhaps this can be explained by the healthy (absence of major systemic diseases and non-smokers) and well-maintained population recruited for this study.

Abutment height has been recently reported to influence the supracrestal tissues establishment around implants irrespective of vertical mucosal thickness (Spinato et al., 2019). In the present study, we observed greater peri-implant bone loss when short abutments $(1.5 \mathrm{~mm})$ were utilized to restore equicrestally positioned implants in areas with thinner mucosa. Similar findings have been previously published by other groups (Galindo-Moreno et al., 2016; Novoa et al., 2017; Pico et al., 2019; Spinato et al., 2019). However, further statistical analysis regarding abutment height could not be performed due to the restricted sample size which could be considered a limitation of the present study.

Deeper implant placement could potentially be linked to deeper pocketing and greater inflammation. However, in the present study, 
TABLE 5 Abutments heights utilized in the study and average peri-implant $\mathrm{CB}$ loss at 60 -month evaluation

\begin{tabular}{|lrl|}
$\begin{array}{l}\text { Length/number of } \\
\text { abutments }(n=55)\end{array}$ & $\begin{array}{l}\text { Implant Apico- } \\
\text { Coronal Position }\end{array}$ & $\begin{array}{l}\text { Peri-implant bone loss } \\
(\text { Mean } \pm \text { SD) mm }\end{array}$ \\
\hline $1.5 \mathrm{~mm}(n=3)$ & $\begin{array}{l}\text { Equicrestal }(n=3) \\
\text { Subcrestal }(n=0)\end{array}$ & $\begin{array}{l}1.94 \pm 0.62 \\
\text { N/A }\end{array}$ \\
\hline $2.5 \mathrm{~mm}(n=19)$ & Equicrestal $(n=19)$ & $0.79 \pm 0.29$ \\
& Subcrestal $(n=0)$ & N/A \\
\hline $3.5 \mathrm{~mm}(n=11)$ & Equicrestal $(n=1)$ & 0.64 \\
& Subcrestal $(n=10)$ & $0.62 \pm 0.4$ \\
\hline $4.5 \mathrm{~mm}(n=22)$ & Equicrestal $(n=3)$ & $0.88 \pm 0.37$ \\
& Subcrestal $(n=19)$ & $1.00 \pm 0.61$ \\
\hline
\end{tabular}

deeper probing measurements indicative of peri-implant pocketing and signs of peri-implant inflammation along with progressive peri-implant bone loss were found in 2 equicrestal implants at the 5 -year follow-up. No peri-implantitis was diagnosed for any of the subcrestal implants. The incidence of peri-implantitis of $3.63 \%$ at implant level and $9.1 \%$ at the patient level were lower when compared to the other reported data (Derks et al., 2016; Derks \& Tomasi, 2015; French, Grandin, \& Ofec, 2019).

Soft tissue recession was not significantly different at the 4- and 8-month timepoints compared to baseline, but significantly increased by the end of the 60-month follow-up period. This phenomenon could potentially be explained by the fact that alveoloplasty was performed before implant placement and this might result in extra tissue thickness that gradually contracted after bone remodeling and biological width (supracrestal fiber attachment) establishment (Berglundh \& Lindhe, 1996). There was no significant difference in soft tissue recession between sub- and equicrestal implants and VMT did not influence the outcome. Since CB levels around all implants were similar, and according to a previous classical study (Kan, Rungcharassaeng, Umezu, $\&$ Kois, 2003) the crestal bone level dictates the level of the mucosal margin, this may explain the absence of a correlation between soft tissue recession and different placement depths.

One limitation of this study is that a wide range of subcrestal implant placement (1-3 mm) was selected to achieve enough primary stability. Ideally, we should have evaluated the impact of each implant depth on bone loss, although due to the small number of patients it was not possible. Additionally, the application of an immediate loading protocol with the one abutment-one time concept may present advantages compared to two stages protocols regarding crestal bone changes, and therefore caution should be taken when analyzing the present outcome.

\section{5 | CONCLUSION}

Within the limitations found in the present study, different implant placement depths and vertical mucosal thickness showed no statistically significant influence on crestal bone level changes and soft tissue recession after 5 years of follow-up. However, subcrestal implant placement had less bone loss and resulted in no implant thread exposure, whereas with equicrestal placement, thread exposure occurred in one implant after 5-year follow-up. It is, therefore, speculated that a subcrestal implant placement of at least $1 \mathrm{~mm}$ can prevent possible biological complications due to implant rough surface exposure.

\section{ACKNOWLEDGEMENTS}

The authors wish to thank Neodent (Curitiba, PR, Brazil) for providing implants and implant components. The authors would also like to thank Dr. Matthew Galli (Department of Periodontics and Oral Medicine, University of Michigan School of Dentistry) for his contribution on the preparation of the manuscript.

\section{CONFLICT OF INTEREST}

The authors do not have any conflict of interest.

\section{AUTHOR'S CONTRIBUTION}

RACS performed treatment, collected the data, and led the writing. RSCJ collected the data and helped with patient management. PGFS performed treatment and collected the data. IAMS conceived the ideas and revised manuscript. HLW analyzed the data and revised manuscript. FNGKF conceived the ideas, analyzed the data, and revised manuscript.

\section{ORCID}

Rafael Amorim Cavalcanti de Siqueira iD https://orcid. org/0000-0003-4081-0959

Hom-Lay Wang iD https://orcid.org/0000-0003-4238-1799

\section{REFERENCES}

Al Amri, M. D., Al-Johany, S. S., Al Baker, A. M., Al Rifaiy, M. Q., Abduljabbar, T. S., \& Al-Kheraif, A. A. (2017). Soft tissue changes and crestal bone loss around platform-switched implants placed at crestal and subcrestal levels: $36-$ month results from a prospective split-mouth clinical trial. Clinical Oral Implants Research, 28(11), 13421347. https://doi.org/10.1111/clr.12990

Atieh, M. A., Tawse-Smith, A., Alsabeeha, N. H. M., Ma, S., \& Duncan, W. J. (2017). The one abutment-one time protocol: A systematic review and meta-analysis. Journal of Periodontology, 88(11), 1173-1185. https://doi.org/10.1902/jop.2017.170238

Barros, R. R., Novaes, A. B. Jr, Muglia, V. A., lezzi, G., \& Piattelli, A. (2010). Influence of interimplant distances and placement depth on peri-implant bone remodeling of adjacent and immediately loaded Morse cone connection implants: A histomorphometric study in dogs. Clinical Oral Implants Research, 21(4), 371-378. https://doi. org/10.1111/j.1600-0501.2009.01860.x

Berglundh, T., Armitage, G., Araujo, M. G., Avila-Ortiz, G., Blanco, J., Camargo, P. M., ... Zitzmann, N. (2018). Peri-implant diseases and conditions: Consensus report of workgroup 4 of the 2017 World Workshop on the Classification of Periodontal and Peri-Implant Diseases and Conditions. Journal of Clinical Periodontology, 45(Suppl 20), S286-S291. https://doi.org/10.1111/jcpe.12957

Berglundh, T., \& Lindhe, J. (1996). Dimension of the periimplant mucosa. Journal of Clinical Periodontology, 23(10), 971-973. https://doi. org/10.1111/j.1600-051X.1996.tb00520.x

Bonino, F., Steffensen, B., Natto, Z., Hur, Y., Holtzman, L. P., \& Weber, H. P. (2018). Prospective study of the impact of peri-implant soft tissue 
properties on patient-reported and clinically assessed outcomes. Journal of Periodontology, 89(9), 1025-1032. https://doi.org/10.1002/ JPER.18-0031

Borges, A. F., Dias Pereira, L. A., Thome, G., Melo, A. C., \& de Mattias Sartori, I. A. (2010). Prostheses removal for suture removal after immediate load: Success of implants. Clinical Implant Dentistry and Related Research, 12(3), 244-248. https://doi. org/10.1111/j.1708-8208.2009.00157.x

Broggini, N., McManus, L. M., Hermann, J. S., Medina, R. U., Oates, T. W., Schenk, R. K., ... Cochran, D. L. (2003). Persistent acute inflammation at the implant-abutment interface. Journal of Dental Research, 82(3), 232-237. https://doi.org/10.1177/154405910308200316

Brunner, E., Domhof, S., \& Langer, F. (2002). Non-parametric analysis of longitudinal data in factorial experiments. New York, NY: J. Wiley.

Canullo, L., Bignozzi, I., Cocchetto, R., Cristalli, M. P., \& lannello, G. (2010). Immediate positioning of a definitive abutment versus repeated abutment replacements in post-extractive implants: 3-year follow-up of a randomised multicentre clinical trial. European Journal of Oral Implantology, 3(4), 285-296.

Canullo, L., Camacho-Alonso, F., Tallarico, M., Meloni, S. M., Xhanari, E., \& Penarrocha-Oltra, D. (2017). Mucosa thickness and peri-implant crestal bone stability: A clinical and histologic prospective cohort trial. International Journal of Oral and Maxillofacial Implants, 32(5), 675-681. https://doi.org/10.11607/jomi.5349

Castro, D. S., Araujo, M. A., Benfatti, C. A., Araujo Cdos, R., Piattelli, A., Perrotti, V., \& lezzi, G. (2014). Comparative histological and histomorphometrical evaluation of marginal bone resorption around external hexagon and Morse cone implants: An experimental study in dogs. Implant Dentistry, 23(3), 270-276. https://doi.org/10.1097/ ID.0000000000000089

Cosyn, J., Sabzevar, M. M., \& De Bruyn, H. (2012). Predictors of inter-proximal and midfacial recession following single implant treatment in the anterior maxilla: A multivariate analysis. Journal of Clinical Periodontology, 39(9), 895-903. https://doi. org/10.1111/j.1600-051X.2012.01921.x

de Mattias Sartori, I. A., da Silveira Junior, C. D., Fontao, F. N., \& da Gloria Chiarello de Mattos, M. (2014). Evaluation of radiographic technique using a new customized film holder for dental implant assessment. Implant Dentistry, 23(1), 13-17. https://doi.org/10.1097/ID.00000 00000000010

de Siqueira, R. A. C., Fontao, F., de Mattias Sartori, I. A., Santos, P. G. F., Bernardes, S. R., \& Tiossi, R. (2017). Effect of different implant placement depths on crestal bone levels and soft tissue behavior: A randomized clinical trial. Clinical Oral Implants Research, 28(10), 1227-1233. https://doi.org/10.1111/clr.12946

Degidi, M., Nardi, D., \& Piattelli, A. (2011). One abutment at one time: Non-removal of an immediate abutment and its effect on bone healing around subcrestal tapered implants. Clinical Oral Implants Research, 22(11), 1303-1307. https://doi. org/10.1111/j.1600-0501.2010.02111.x

D'Ercole, S., Tripodi, D., Ravera, L., Perrotti, V., Piattelli, A., \& lezzi, G. (2014). Bacterial leakage in Morse Cone internal connection implants using different torque values: An in vitro study. Implant Dentistry, 23(2), 175-179. https://doi.org/10.1097/ID.0000000000000044

Derks, J., Schaller, D., Hakansson, J., Wennstrom, J. L., Tomasi, C., \& Berglundh, T. (2016). Effectiveness of implant therapy analyzed in a Swedish population: Prevalence of peri-implantitis. Journal of Dental Research, 95(1), 43-49. https://doi.org/10.1177/0022034515 608832

Derks, J., \& Tomasi, C. (2015). Peri-implant health and disease. A systematic review of current epidemiology. Journal of Clinical Periodontology, 42, S158-S171. https://doi.org/10.1111/jcpe.12334

Fetner, M., Fetner, A., Koutouzis, T., Clozza, E., Tovar, N., Sarendranath, A., ... Neiva, R. (2015). The effects of subcrestal implant placement on crestal bone levels and bone-to-abutment contact: A microcomputed tomographic and histologic study in dogs. International Journal of Oral and Maxillofacial Implants, 30(5), 1068-1075. https://doi. org/10.11607/jomi.4043

French, D., Grandin, H. M., \& Ofec, R. (2019). Retrospective cohort study of 4,591 dental implants: Analysis of risk indicators for bone loss and prevalence of peri-implant mucositis and peri-implantitis. Journal of Periodontology, 90(7), 691-700. https://doi.org/10.1002/ JPER.18-0236

Fu, J. H., Lee, A., \& Wang, H. L. (2011). Influence of tissue biotype on implant esthetics. International Journal of Oral and Maxillofacial Implants, 26(3), 499-508.

Galindo-Moreno, P., Leon-Cano, A., Monje, A., Ortega-Oller, I., O'Valle, F., \& Catena, A. (2016). Abutment height influences the effect of platform switching on peri-implant marginal bone loss. Clinical Oral Implants Research, 27(2), 167-173. https://doi.org/10.1111/clr.12554

Grischke, J., Karch, A., Wenzlaff, A., Foitzik, M. M., Stiesch, M., \& Eberhard, J. (2019). Keratinized mucosa width is associated with severity of peri-implant mucositis. A cross-sectional study. Clinical Oral Implants Research, 30(5), 457-465. https://doi.org/10.1111/ clr.13432

Gualini, F., Salina, S., Rigotti, F., Mazzarini, C., Longhin, D., Grigoletto, M., ... Esposito, M. (2017). Subcrestal placement of dental implants with an internal conical connection of $0.5 \mathrm{~mm}$ versus $1.5 \mathrm{~mm}$ : Outcome of a multicentre randomised controlled trial 1 year after loading. European Journal of Oral Implantology, 10(1), 73-82.

Hermann, J. S., Cochran, D. L., Nummikoski, P. V., \& Buser, D. (1997). Crestal bone changes around titanium implants. A radiographic evaluation of unloaded nonsubmerged and submerged implants in the canine mandible. Journal of Periodontology, 68(11), 1117-1130. https ://doi.org/10.1902/jop.1997.68.11.1117

Kan, J. Y., Rungcharassaeng, K., Umezu, K., \& Kois, J. C. (2003). Dimensions of peri-implant mucosa: An evaluation of maxillary anterior single implants in humans. Journal of Periodontology, 74(4), 557-562. https://doi.org/10.1902/jop.2003.74.4.557

Khorshidi, H., Raoofi, S., Moattari, A., Bagheri, A., \& Kalantari, M. H. (2016). In vitro evaluation of bacterial leakage at implant-abutment connection: An 11-degree Morse taper compared to a butt joint connection. International Journal of Biomaterials, 2016, 8527849. https:// doi.org/10.1155/2016/8527849

Koh, R. U., Oh, T. J., Rudek, I., Neiva, G. F., Misch, C. E., Rothman, E. D., \& Wang, H. L. (2011). Hard and soft tissue changes after crestal and subcrestal immediate implant placement. Journal of Periodontology, 82(8), 1112-1120. https://doi.org/10.1902/jop.2011.100541

Koutouzis, T., Neiva, R., Nair, M., Nonhoff, J., \& Lundgren, T. (2014). Cone beam computed tomographic evaluation of implants with platform-switched Morse taper connection with the implant-abutment interface at different levels in relation to the alveolar crest. International Journal of Oral and Maxillofacial Implants, 29(5), 11571163. https://doi.org/10.11607/jomi.3411

Lazzara, R. J., \& Porter, S. S. (2006). Platform switching: A new concept in implant dentistry for controlling postrestorative crestal bone levels. International Journal of Periodontics \& Restorative Dentistry, 26(1), 9-17.

Lee, H. J., de Mattias Sartori, A. I., Alcantara, P. R., Vieira, R. A., Suzuki, D., Gasparini Kiatake Fontão, F., \& Tiossi, R. (2012). Implant stability measurements of two immediate loading protocols for the edentulous mandible: Rigid and semi-rigid splinting of the implants. Implant Dentistry, 21(6), 486-490. https://doi.org/10.1097/ID.0b013e3182 6b1c68

Lin, G. H., Chan, H. L., \& Wang, H. L. (2013). The significance of keratinized mucosa on implant health: A systematic review. Journal of Periodontology, 84(12), 1755-1767. https://doi.org/10.1902/ jop.2013.120688

Linkevicius, T., Apse, P., Grybauskas, S., \& Puisys, A. (2009). The influence of soft tissue thickness on crestal bone changes around implants: A 
1-year prospective controlled clinical trial. International Journal of Oral and Maxillofacial Implants, 24(4), 712-719.

Linkevicius, T., Apse, P., Grybauskas, S., \& Puisys, A. (2010). Influence of thin mucosal tissues on crestal bone stability around implants with platform switching: A 1-year pilot study. Journal of Oral and Maxillofacial Surgery, 68(9), 2272-2277. https://doi.org/10.1016/j. joms.2009.08.018

Linkevicius, T., Linkevicius, R., Alkimavicius, J., Linkeviciene, L., Andrijauskas, P., \& Puisys, A. (2018). Influence of titanium base, lithium disilicate restoration and vertical soft tissue thickness on bone stability around triangular-shaped implants: A prospective clinical trial. Clinical Oral Implants Research, 29(7), 716-724. https://doi. org/10.1111/clr.13263

Linkevicius, T., Puisys, A., Steigmann, M., Vindasiute, E., \& Linkeviciene, L. (2015). Influence of vertical soft tissue thickness on crestal bone changes around implants with platform switching: A comparative clinical study. Clinical Implant Dentistry and Related Research, 17(6), 1228-1236. https://doi.org/10.1111/cid.12222

Meijer, H. J. A., Boven, C., Delli, K., \& Raghoebar, G. M. (2018). Is there an effect of crown-to-implant ratio on implant treatment outcomes? A systematic review. Clinical Oral Implants Research, 29(Suppl 18), 243-252. https://doi.org/10.1111/clr.13338

Monje, A., Galindo-Moreno, P., Tozum, T. F., Suarez-Lopez del Amo, F., \& Wang, H. L. (2016). Into the paradigm of local factors as contributors for peri-implant disease: Short communication. International Journal of Oral and Maxillofacial Implants, 31(2), 288-292. https://doi. org/10.11607/jomi.4265

Novaes, A. B. Jr, Barros, R. R., Muglia, V. A., \& Borges, G. J. (2009). Influence of interimplant distances and placement depth on papilla formation and crestal resorption: A clinical and radiographic study in dogs. Journal of Oral Implantology, 35(1), 18-27. https://doi. org/10.1563/1548-1336-35.1.18

Novoa, L., Batalla, P., Caneiro, L., Pico, A., Linares, A., \& Blanco, J. (2017). Influence of abutment height on maintenance of peri-implant $\mathrm{cr}$ estal bone at bone-level implants: A 3-year follow-up study. The International Journal of Periodontics \& Restorative Dentistry, 37(5), 721-727. https://doi.org/10.11607/prd.2762

Oh, T. J., Yoon, J., Misch, C. E., \& Wang, H. L. (2002). The causes of early implant bone loss: Myth or science? Journal of Periodontology, 73(3), 322-333. https://doi.org/10.1902/jop.2002.73.3.322

Palaska, I., Tsaousoglou, P., Vouros, I., Konstantinidis, A., \& Menexes, G. (2016). Influence of placement depth and abutment connection pattern on bone remodeling around 1-stage implants: A prospective randomized controlled clinical trial. Clinical Oral Implants Research, 27(2), e47-e56. https://doi.org/10.1111/clr.12527

Pellicer-Chover, H., Penarrocha-Diago, M., Penarrocha-Oltra, D., GomarVercher, S., Agustin-Panadero, R., \& Penarrocha-Diago, M. (2016). Impact of crestal and subcrestal implant placement in peri-implant bone: A prospective comparative study. Medicina Oral Patología Oral Y Cirugia Bucal, 21(1), e103-e110. https://doi.org/10.4317/medor al.20747

Perussolo, J., Souza, A. B., Matarazzo, F., Oliveira, R. P., \& Araujo, M. G. (2018). Influence of the keratinized mucosa on the stability of peri-implant tissues and brushing discomfort: A 4-year follow-up study. Clinical Oral Implants Research, 29(12), 1177-1185. https://doi. org/10.1111/clr.13381

Pico, A., Martin-Lancharro, P., Caneiro, L., Novoa, L., Batalla, P., \& Blanco, J. (2019). Influence of abutment height and implant depth position on interproximal peri-implant bone in sites with thin mucosa: A 1-year randomized clinical trial. Clinical Oral Implants Research, 30(7), 595602. https://doi.org/10.1111/clr.13443

Pistilli, R., Genova, T., Canullo, L., Faga, M. G., Terlizzi, M. E., Gribaudo, G., \& Mussano, F. (2018). Effect of bioactivation on traditional surfaces and zirconium nitride: Adhesion and proliferation of preosteoblastic cells and bacteria. International Journal of Oral and
Maxillofacial Implants, 33(6), 1247-1254. https://doi.org/10.11607/ jomi.6654

Pontes, A. E., Ribeiro, F. S., da Silva, V. C., Margonar, R., Piattelli, A., Cirelli, J. A., \& Marcantonio, E. Jr (2008). Clinical and radiographic changes around dental implants inserted in different levels in relation to the crestal bone, under different restoration protocols, in the dog model. Journal of Periodontology, 79(3), 486-494. https://doi.org/10.1902/ jop.2008.070145

Promsudthi, A., Pimapansri, S., Deerochanawong, C., \& Kanchanavasita, W. (2005). The effect of periodontal therapy on uncontrolled type 2 diabetes mellitus in older subjects. Oral Diseases, 11(5), 293-298. https://doi.org/10.1111/j.1601-0825.2005.01119.x

Ravida, A., Wang, I. C., Barootchi, S., Askar, H., Tavelli, L., GargalloAlbiol, J., \& Wang, H. L. (2019). Meta-analysis of randomized clinical trials comparing clinical and patient-reported outcomes between extra-short $(</=6 \mathrm{~mm})$ and longer $(>/=10 \mathrm{~mm})$ implants. Journal of Clinical Periodontology, 46(1), 118-142. https://doi.org/10.1111/ jcpe.13026

Renvert, S., Persson, G. R., Pirih, F. Q., \& Camargo, P. M. (2018). Periimplant health, peri-implant mucositis, and peri-implantitis: Case definitions and diagnostic considerations. Journal of Clinical Periodontology, 45(Suppl 20), S278-S285. https://doi.org/10.1111/ jcpe.12956

Roccuzzo, M., Grasso, G., \& Dalmasso, P. (2016). Keratinized mucosa around implants in partially edentulous posterior mandible: 10 -year results of a prospective comparative study. Clinical Oral Implants Research, 27(4), 491-496. https://doi.org/10.1111/clr.12563

Romanos, G. E., Aydin, E., Gaertner, K., \& Nentwig, G. H. (2015). Longterm results after subcrestal or crestal placement of delayed loaded implants. Clinical Implant Dentistry and Related Research, 17(1), 133141. https://doi.org/10.1111/cid.12084

Rompen, E. (2012). The impact of the type and configuration of abutments and their (repeated) removal on the attachment level and marginal bone. European Journal of Oral Implantology, 5(Suppl), S83-S90.

Saleh, M. H. A., Ravida, A., Suarez-Lopez Del Amo, F., Lin, G. H., Asa'ad, F., \& Wang, H. L. (2018). The effect of implant-abutment junction position on crestal bone loss: A systematic review and meta-analysis. Clinical Implant Dentistry and Related Research, 20(4), 617-633. https ://doi.org/10.1111/cid.12600

Schwarz, F., Becker, K., Sahm, N., Horstkemper, T., Rousi, K., \& Becker, J. (2017). The prevalence of peri-implant diseases for two-piece implants with an internal tube-in-tube connection: A cross-sectional analysis of 512 implants. Clinical Oral Implants Research, 28(1), 24-28. https://doi.org/10.1111/clr.12609

Spinato, S., Stacchi, C., Lombardi, T., Bernardello, F., Messina, M., \& Zaffe, D. (2019). Biological width establishment around dental implants is influenced by abutment height irrespective of vertical mucosal thickness: A cluster randomized controlled trial. Clinical Oral Implants Research, 30(7), 649-659. https://doi.org/10.1111/clr.13450

Tarnow, D. P., Cho, S. C., \& Wallace, S. S. (2000). The effect of inter-implant distance on the height of inter-implant bone crest. Journal of Periodontology, 71(4), 546-549. https://doi.org/10.1902/ jop.2000.71.4.546

Tenenbaum, H., Schaaf, J. F., \& Cuisinier, F. J. (2003). Histological analysis of the Ankylos peri-implant soft tissues in a dog model. Implant Dentistry, 12(3), 259-265. https://doi.org/10.1097/01.ID.00000 75720.78252 .54

Teughels, W., Van Assche, N., Sliepen, I., \& Quirynen, M. (2006). Effect of material characteristics and/or surface topography on biofilm development. Clinical Oral Implants Research, 17(Suppl 2), 68-81. https ://doi.org/10.1111/j.1600-0501.2006.01353.x

Thome, E., Lee, H. J., de Mattias Sartori, I. A., Trevisan, R. L., Luiz, J., $\&$ Tiossi, R. (2015). A randomized controlled trial comparing interim acrylic prostheses with and without cast metal base for immediate loading of dental implants in the edentulous mandible. Clinical 
Oral Implants Research, 26(12), 1414-1420. https://doi.org/10.1111/ clr.12470

van Eekeren, P., van Elsas, P., Tahmaseb, A., \& Wismeijer, D. (2017). The influence of initial mucosal thickness on crestal bone change in similar macrogeometrical implants: A prospective randomized clinical trial. Clinical Oral Implants Research, 28(2), 214-218. https://doi. org/10.1111/clr.12784

Vervaeke, S., Matthys, C., Nassar, R., Christiaens, V., Cosyn, J., \& De Bruyn, H. (2018). Adapting the vertical position of implants with a conical connection in relation to soft tissue thickness prevents early implant surface exposure: A 2-year prospective intra-subject comparison. Journal of Clinical Periodontology, 45(5), 605-612. https://doi. org/10.1111/jcpe.12871

Weng, D., Nagata, M. J., Bell, M., Bosco, A. F., de Melo, L. G., \& Richter, E. J. (2008). Influence of microgap location and configuration on the periimplant bone morphology in submerged implants. An experimental study in dogs. Clinical Oral Implants Research, 19(11), 1141-1147. https://doi.org/10.1111/j.1600-0501.2008.01564.x

Weng, D., Nagata, M. J., Bosco, A. F., \& de Melo, L. G. (2011). Influence of microgap location and configuration on radiographic bone loss around submerged implants: An experimental study in dogs. International Journal of Oral and Maxillofacial Implants, 26(5), 941-946.
Weng, D., Nagata, M. J., Leite, C. M., de Melo, L. G., \& Bosco, A. F. (2011). Influence of microgap location and configuration on radiographic bone loss in nonsubmerged implants: An experimental study in dogs. The International Journal of Prosthodontics, 24(5), 445-452.

\section{SUPPORTING INFORMATION}

Additional supporting information may be found online in the Supporting Information section.

How to cite this article: de Siqueira RAC, Savaget Gonçalves Junior R, dos Santos PGF, de Mattias Sartori IA, Wang H-L, Fontão FNGK. Effect of different implant placement depths on crestal bone levels and soft tissue behavior: A 5-year randomized clinical trial. Clin Oral Impl Res. 2020;31:282-293. https://doi.org/10.1111/clr.13569 